diejenige, welche jene orangefarbene Verbindung unter gleichen Umständen erlitt, so wurde, da von dem Oxyd auch mehr zu Gebote stand, das sich daraus entwickelnde Gas seinen Eigenschaften nach verfolgt und man überzeugte sich, dass es nur atmosphärische Luft war, die man ja auch beim Uebergiessen des seiner Kohlensäure beraubten Zinkoxyds mit Säuren oder auch mit Wasser auftreten sieht. Die nähern Eigenschaften jener orangefarbenen Verbindung konnte, da nur eine geringe Menge zu Gebote stand und eine genaue Trennung von dem noch unzersetzten basischen Salz unmöglich war, nicht weiter studirt werden. Uebrigens liegt der Gedanke sehr nahe, dass es irgend eine Verbindung eines Zersetzungsproducts der Salpetersäure mit dem Wismuthoxyd sei, um so mehr, da es dem noch ganz unzersetzten Kern der Masse am nüchsten lag.

\title{
Analyse menschlicher Harnsteine;
}

\author{
von
}

\section{Dr. Reich in Königsberg in Preussen.}

Von dem Herrn Prof. Dr. Seerig hieselbst wurden mir kürzlich zermalmte Stückchen von zwei verschiedenen Harnsteinen von Menschen zur chemischen Untersuchung eingehändigt. An dem Durchschnitt der Stückchen von dem einen Harnstein A. sind mehrere Schichten bemerkbar, wovon die äusseren eine braungelbe, die inneren eine hell gelbgrave Färbung zeigen, deren Bruchfläche nicht krystallinisch, sondern erdig ist. Ein Stückchen davon, auf einem Platinblech erhitzt, färbte sich schwarz und verfluichtigte sich ohne zu schmelzen, fast selbstständig bis auf einen kaum bemerkbaren Rückstand, unter Entwicklung eines animalischen Geruchs. Die mit dieser Concretion A. nach bekannter Methode vorgenommene chemische Analyse ergab folgendes Resultat: 
Hlarnsäure........................ 58,45

Saures harnsaures Ammoniak .............. 3i,83

Sogenannter Extractivstoff (Harnfarbstoff), in Alkohol

löslich, theils durch Wasser daraus fällbar .... $6,3 \mathfrak{l}$

In Wasser und Essigsäure löslicher gelber Farbstoff 2,62

Blasenschleim ......................... 0,46

Fett $\ldots \ldots \ldots \ldots \ldots \ldots \ldots \ldots \ldots \ldots \ldots, \quad 0,33$

100,00 .

Die Stückchen des zermalmten zweiten Harnsteins B. besitzen eine hellgrau gelbliche Färbung, an dem Durchschnitt eine concentrische Schichtung bemerkbar und deren Bruchfläche erdig ist. Auf einem Platinblech erhitzt, verbreitet diese Concretion einen starken Geruch nach empyreumatischen thierischen Producten (nach gebrannten Knochen), während dem es sich stark schwärzt. Nach stärkerm und längerm Glühen wird die Schwärzung unbedeutend heller. Durch Salzsäure wird dieser Harnstein unter starkem Aufbrausen aufgelöst.

Die chemische Analyse nach bekannter Methode gab folgende merkwürdige Zusammensetzung:

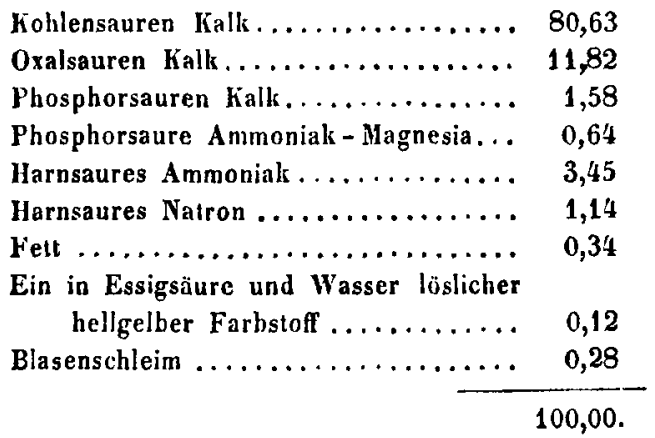

